\title{
Revista
}

(Ropp) Gestão \& Políticas Públicas

Artigo

\section{Nota Fiscal Paulista: um estudo exploratório sobre o comportamento do cidadão da geração Y na grande São Paulo}

\author{
São Paulo Tax Invoice: an exploratory research about behavior's \\ citizen of Y generation in great São Paulo
}

Nota fiscal Paulista: un estudio exploratorio sobre el comportamiento ciudadano de la generación Y en Sao Paulo

Antonio Nunes Pereira ${ }^{1}$, Viviane Vieira de Andrade ${ }^{2}$, Ana Cristina de Faria ${ }^{3}$.

\footnotetext{
${ }^{1}$ Filiação institucional. Mestre em Contabilidade pela Universidade Federal Rural do Rio de Janeiro. Doutor em Administração pelo Programa de Pós-Graduação em Administração da Universidade Municipal de São Caetano do Sul, São Caetano do Sul, SP, Brasil.

Correspondência: E-mail: profanp@gmail.com

2 Filiação institucional. Especialista em Gestão Tributaria. Bacharel em Ciências Contábeis, Divinópolis, MG, Brasil.

Correspondência: E-mail: vivix.andrade@uol.com.br
}

\footnotetext{
${ }^{3}$ Filiação institucional. Doutora e Mestre em Controladoria e Contabilidade (FEA/USP). Professora do Programa de Pós-Graduação em Cidades Inteligentes e Sustentáveis e do Mestrado Profissional em Gestão Ambiental e Sustentabilidade da Universidade Nove de Julho, São Paulo, SP. Brasil.

Correspondência: E-mail: anacfaria@uol.com.br
}

Resumo O objetivo deste estudo é explorar o comportamento de um grupo específico de cidadãos - os da Geração Y (nascidos entre 1980 e 1999), em relação ao sistema do Programa de Incentivo à Cidadania Fiscal - Nota Fiscal Paulista (NFP). A pesquisa de caráter exploratório contemplou 117 respondentes na Grande São Paulo. Os achados da pesquisa possibilitam defender que há forte adesão da amostra pesquisada pertencente à Geração Y $(75,8 \%)$. Parcela significativa dos respondentes (68\%) dessa faixa prefere o crédito em conta corrente, como forma de uso dos benefícios do programa, seguidos de $17 \%$ que optam pelo desconto no Imposto sobre Propriedade de Veículos Automotores - IPVA. As estatísticas descritivas corroboram com 
- quadro teórico-conceitual, de que os representantes da Geração Y são hábeis na utilização de ferramentas ligadas à Tecnologia de Informação; tal como o sistema da NFP, e são atentos aos seus direitos e inclinados a buscarem retornos financeiros imediatos.

Palavras-chaves: Comportamento do Cidadão; Geração Y; Governo Eletrônico; Nota Fiscal Paulista (NFP).

Abstract The purpose of this study is to explore the behavior of a specific group of people - those of $Y$ Generation (borned between 1980 and 1999) in relation to the system of the Program to encourage Citizenship tax - São Paulo Tax Invoice (SPTI). The research of exploratory included 117 respondents in the Great Sao Paulo. The findings of research enable defend that there is strong attachment of the sample surveyed belonging to $Y$ Generation (75.8\%). Significant portion of the respondents $(68 \%)$ of that band prefers the credit to current account as a way to use the benefits of the program, followed by $17 \%$ opting for discount in highway tolls. The descriptive statistics corroborate with the theoretical framework and conceptual in that the representatives of Generation $Y$ are skillful in the use of tools related to Information Technology; such as the system of SPTI, and are attentive to their rights and inclined to seek financial returns immediately.

Keywords: Behavior; Citizen; E-Government; São Paulo Tax Invoice; Y Generation.

Resumen El objetivo de este estudio es explorar el comportamiento de un grupo particular de ciudadanos - los de la Generación Y (nacidos entre 1980 y 1999) en relación con el Programa de Incentivos para el sistema a la ciudadanía fiscal - Nota Fiscal Paulista (PFN). La encuesta exploratoria incluyó 117 encuestados en la Gran Sao Paulo. Los resultados de la investigación permiten argumentar que existe un fuerte apoyo de ejemplo de investigación perteneciente a la Generación Y $(75,8 \%)$. Una proporción significativa de los encuestados (68\%) de este grupo prefiere la cuenta corriente de crédito como una manera de utilizar los beneficios del programa, seguido por el $17 \%$ que optan por el descuento sobre el impuesto sobre los vehículos de motor de propiedad - impuestos sobre la propiedad. La estadística descriptiva corroboran el marco teórico y conceptual que los representantes de la Generación Y son expertos en el uso de herramientas relacionadas con la tecnología de la información; como el sistema de la PFN, y son concientes de sus derechos y dispuestos a buscar la rentabilidad financiera inmediata.

Palabras Clave: Comportamiento de los ciudadanos; Generación Y; Gobierno electrónico; Nota Fiscal Paulista (PFN). 


\section{Introdução}

Este trabalho focaliza o uso da Nota Fiscal Paulista (NFP), instrumento utilizado pela Administração Pública Paulista por meio do Programa de Incentivo à Cidadania Fiscal para combater a sonegação fiscal por um grupo de contribuintes muito peculiar, a Geração Y (que contempla o grupo de indivíduos nascidos entre 1980 e 1999).

Trata-se de uma política inovadora, fruto de mudanças sociais e na gestão pública fazendária paulista, que demonstra o empenho do fisco em fortalecer e desenvolver instrumentos que garantam uma arrecadação mais eficiente (Matto, Rocha, \& Toporcov, 2013). O encontro da NFP com a nova geração de cidadãos a Geração Y propicia, portanto, um fenômeno muito peculiar e pouco explorado na literatura e que esta pesquisa irá abordar.

Fregonesi Júnior (2010) defende que o estudo das origens e das aplicações, formas de crédito, perfil de consumo, evolução na legislação e operações e o regime de retorno dos créditos é benéfico para o Estado e para o contribuinte, visto exclusivamente no universo do fiscalizador. Pode-se considerar que outros agentes sociais, a exemplo de contribuintes, comerciantes e pesquisadores, também tenham interesse no comportamento do contribuinte.

Os usos sociais alternativos dos créditos com a doação dos créditos da Nota Fiscal Paulista reforçam a perspectiva que orienta a presente pesquisa. Assim, este estudo focaliza os elementos que possibilitem a compreensão do sistema da NFP e o uso por uma faixa de contribuintes mais jovens e formas de utilização dos créditos recebidos como benefícios, sem perder a visão crítica dos aspectos que o cercam, benefícios e dificuldades encontradas para utilização.

Os problemas que norteiam esta pesquisa podem ser enunciados nas seguintes questões: a) A Geração Y está se cadastrando no sistema da NFP? Qual a preferência de utilização dos créditos da NFP pela Geração Y? Quais os benefícios da adoção da NFP sob ótica do cidadão?

O objetivo do estudo é explorar o comportamento de um grupo específico de cidadãos - os da Geração Y em relação ao sistema da NFP. Assim, se pode obter informações sobre mudanças inerentes desse fenômeno e avaliar até que ponto foram obtidos benefícios, tanto para o cidadão quanto para o órgão fiscalizador.

A realização da pesquisa justifica-se em razão do recente histórico de que a implantação da NFP, de acordo com a legislação tributária para o Estado de São Paulo, desde meados de 2007, que exigiu do consumidor/cidadão uma rápida adaptação para que as novas regras fossem seguidas. 


\section{Fundamentação Teórica}

\subsection{Comportamento do Cidadão e a Geração Y}

O comportamento do consumidor, no caso deste estudo, o cidadão, é um dos campos mais complexos relacionados à teoria de Marketing, e reúne contribuições de outras áreas como Psicologia, Sociologia, Antropologia Social e Economia. O desenvolvimento teórico nesse campo de estudos tem-se produzido no âmbito da abordagem das Ciências Comportamentais (Rocha, \& Christensen, 2008).

O consumidor não adota, necessariamente, um único tipo de regra de escolha para suas decisões, que variam de acordo com as alternativas, passando pela sua intenção atitudes e fatores, considerados fundamentais na decisão de compra. Há, então, o relacionamento das atitudes e fatores que possam interferir entre a intenção e a decisão (Kotler, \& Keller, 2006). Nesta pesquisa, há interesse especial pelo fator idade, para evidenciar se este influencia no comportamento do cidadão em relação à NFP, já que mudanças de atitudes e comportamentos dos jovens refletem-se, cada vez mais, na sociedade de hoje.

Pode-se inferir que são estabelecidos padrões de consumo e produção diferentes e os próprios sonhos entre as gerações. Nascidos entre 1980 e 1999, os jovens da Geração Y estão chegando à vida adulta entre seus 23 a 32 anos, ao mercado de trabalho e começam a interferir, de maneira direta, no destino da sociedade. São muito bem informados; mas, também possuem um componente de alienação por não conseguirem lidar com toda essa informação de maneira produtiva. Nasceram em famílias mais flexíveis e o convívio com os familiares é diferente em relação às gerações anteriores.

Pode-se dizer que estaria determinado ao jovem da Geração Y o destino de modificar, profundamente, os paradigmas e premissas estabelecidos. Contudo, isso não pode acontecer sem considerar as características que formaram as gerações anteriores e que, ainda interferem muito no presente e futuro da sociedade (Oliveira, 2010). Este autor destaca que a Geração Y possui características marcantes em sua personalidade e comportamento, que são predominantes nesses jovens e são subdivididas em positivas e negativas identificadas nessa geração.

Para Lipkin e Perrymore (2010), de um modo geral, a Geração Y estabelece e mantém seus relacionamentos de forma totalmente diferente das gerações anteriores, devido à socialização eletrônica. Essa geração garante seus relacionamentos e contatos frequentes com as informações, independentemente de tempo, distância e localização. Esse grupo de indivíduos mantém envolvimento com atividades que enfatizam o contato social. A utilização da ferramenta internet para essa geração é muito natural. 
A Geração Y possui novas formas de pensar, comunicar-se, atuar, de fazer negócios e de buscar seus direitos; que são realidade na cultura da sociedade, por meio do comportamento e suas motivações para adquirir conhecimento e experiências dentro da sociedade, que será refletida em sua vida pessoal e profissional para os jovens dessa geração.

Contempla indivíduos frágeis e inconstantes, que se alteram com uma velocidade estupenda. Entretanto, muito embora exista uma tendência que diferenciaria a Geração $Y$ da anterior, não é possível estabelecer um período exato para cada fase do processo de mudança, ou ainda para a total aceitação e mudanças de comportamentos (Lipkin, \& Perrymore, 2010).

Na visão de Andrade (2010), apesar do peso numérico e da importância das questões que envolvem este segmento populacional, ainda se tem pouca repercussão na formulação de programas de políticas públicas para esse grupo da população. Esse autor acrescenta que algumas questões pertinentes aos jovens foram desconsideradas para atuação de ações públicas estatais, direitos e oportunidades que são palavras-chave na linguagem que caracteriza a atual política nacional de juventude.

Há que se destacar, nesse contexto social, o fato de que a tecnologia criou alternativas e novas possibilidades, em que o Estado pode cumprir suas funções e obrigações, desempenhando seu papel com eficiência e transparência (Mora, 2005). Nesse caso, pode inferir que as práticas tributárias seriam influenciadas por essas questões sócio-demográficas.

A NFP parece representar uma reorganização da gestão fazendária que passa a utilizar incentivos, em detrimento da tradicional abordagem de fiscalização, mormente relacionada à punição. Ainda que não seja encontrado o conceito desenvolvido, pode-se remeter facilmente à NFP aos aspectos de agregação de valor para a gestão fazendária: contribuinte, cidadão e sociedade, atualmente, aumentando sua automatização.

\subsection{Governo Eletrônico no Brasil}

O Governo tem como função organizar e disciplinar a relação entre as pessoas, corrigir e complementar o sistema tributário que se mostra dinâmico (Fregonesi Junior, 2010). Este, por si só, não é capaz de harmonizar todas as funções tributárias e econômicas. Para tal, deve estar presente, normatizando e minimizando os conflitos. Há, nesse contexto, a abertura de um enorme leque de possibilidades com as novas configurações societárias. Esse ambiente de novas tecnologias suscita um conjunto de novas descobertas para informatização de atividades e comunicação disponibilizadas para cidadãos, empresas e demais setores da sociedade. 
A tecnologia viabiliza possibilidades para atingir os objetivos traçados quando se migra para a esfera governamental e política, com a abertura por parte do governo para a transparência e participação societal em todo seu processo histórico e do balanço de forças políticas existentes na sociedade (Pinho, 2008, p. 473).

Paula (2005) ao discutir os limites e potencialidades para uma nova gestão pública, destaca as vertentes - gerencial e societal. A autora questiona quais e até que ponto são eficazes as relações entre o Estado, buscando formas de organização e participação social. Contudo, inegável é que o Estado Brasileiro experimentou propostas para reformular as instituições políticas e a dinâmica administrativa.

Na administração gerencial, destaca-se positivamente a melhoria na eficiência do setor público com a utilização de novas ferramentas e tecnologias. $\mathrm{Na}$ perspectiva societal destaca-se positivamente a participação mais aberta e atendimento às necessidades em projetos que atendam ao interesse dos cidadãos.

A governança eletrônica, no âmbito dos governos, contempla todo o suporte digital para a elaboração de políticas públicas, para a tomada de decisões e a gestão de recursos públicos, financeiros, humanos, de conhecimento, patrimoniais e outros. Esse movimento acarreta progresso da democracia, permitindo que o Estado não cometa arbitrariedades e apresente uma ferramenta útil transparente, flexível e prática para que os contribuintes identifiquem o uso racional de suas contribuições (Lemos, \& Levy, 2010).

Fernandes (2004, p.102) discute acerca do sentido e das implicações para as experiências administrativas públicas, bem o como o Governo Eletrônico ingressou nas agendas governamentais com grande visibilidade. Em síntese, Fernandes (2004) defende que as concepções, o modelos, as tecnologias e os instrumentos associados ao sistema, têm o potencial necessário para aplicar as principais inovações na Administração Pública, orientando o Governo brasileiro nas suas práticas e procedimentos necessários ao cumprimento de suas finalidades e de suprir as necessidades da população.

Chahin e Cunha (2004, p.3) afirmam que a "união das tecnologias de informação e de comunicação eletrônicas digitais convergentes oferece meios poderosos e, cada vez mais baratos, de aperfeiçoar nossa democracia, pagar nossa dívida social e estimular nossa economia". Haldenwang (2004) acredita que o Governo Eletrônico é instrumento para aumentar a eficiência da Administração Pública, melhorar o fornecimento de serviços públicos e reforçar a abertura e a transparência de processos políticos.

Os avanços em termos de governo eletrônico criam um ambiente propício ao desenvolvimento e aprofundamento das relações intergovernamentais, 
possibilitando a consolidação e implantação dos projetos, mostrando força no Governo Eletrônico (Mora 2005, p.28).

Quando se inicia a implantação de um sistema de informação de uma entidade pública, podem-se imaginar as estruturas burocráticas e isoladas do contexto que se deve operar na obtenção dos resultados da implantação dos sistemas eletrônicos (Fugini, Maggiolini, \& Pagamici, 2005).

Coelho (2001, p.120) destaca que com um programa de mudança e modernização ao utilizar-se a tecnologia da informação na gestão pública, os resultados são positivos e orientados ao cidadão. Os mesmos acabam por refletir em melhorias, na forma como o Governo elabora suas políticas; avalia a qualidade dos serviços prestados; provê serviços de interesse da sociedade; utiliza as novas tecnologias e valoriza o serviço público.

Na visão de Almeida (2010, p. 2), o uso da internet como Tecnologia de Informação (TI) pelos Governos, com o intuito de atender aos princípios que, usualmente, norteiam a implantação do e-government, pauta-se na democratização do acesso à informação e na universalização dos serviços públicos.

No Brasil, a expressão e-gov é empregada para indicar serviços eletrônicos disponibilizados pelo Governo Federal, entre eles: a entrega de declarações, divulgações de editais governamentais e institucionais sobre benefícios da previdência, visando à modernização da Administração Pública por meio do uso da TI (Diniz et. al., 2009).

Pinho (2008, p.484), por sua vez, defende que a Tl acaba por potencializar novos comportamentos de cidadania, eficiência administrativa e fomentar práticas de controle social. Uma sociedade que, cada vez mais, faz uso de tecnologias, recursos digitais, a criação de facilidade de acesso e busca pela informação toma como fundamental a prestação de contas e informações sobre a Administração Pública por meio de divulgação em portais do Governo.

Os avanços nessa área de $\mathrm{Tl}$ interligam o mundo por meio da Internet, garantindo a expansão da Economia, e passam a colaborar com os Governos no exercício de suas funções. O alvo principal do Governo Eletrônico é melhorar o desempenho interno e externo do setor público (Schedler, \& Scharf, 2001).

O Brasil desponta como líder em Governo Eletrônico entre os países em desenvolvimento; entretanto, esse movimento desenvolve-se em nível mundial e há várias experiências comprovadamente exequíveis que, com adaptações poderiam ser utilizadas no Brasil com sucesso. Entre os países que dispõem de legislação sobre o assunto, estão a Argentina, Chile, México, Costa Rica, Colômbia e Austrália, além dos países da União Européia, em função da adoção da Diretiva 115/2001. 
O Governo brasileiro, que tem despontado como líder em Governo Eletrônico entre os países em desenvolvimento, vem utilizando a experiência de outros países como modelo, tais como: Espanha, Chile e México, e entrou na era digital com o SPED - Sistema Público de Escrituração Digital, visando a aproximar o fisco de seus contribuintes (Brasil, 2015).

O SPED é um projeto que foi instituído em 2007 pelo Ministério da Fazenda e faz parte do Programa de Aceleração do Crescimento (PAC) do Governo Federal brasileiro. Constitui em avanço nas relações entre o fisco e os contribuintes e cidadãos e consiste na modernização da sistemática atual de cumprimento das obrigações acessórias, utilizando-se de certificação digital (Pereira et. al., 2008, p. 6).

Pereira et. al. (2008) destacam que o site do Ministério da Fazenda deixa claro que, antes de ser um simples instrumento de aumento de arrecadação, o SPED pretende proporcionar melhor ambiente de negócio para o País e redução de custos para todos os agentes da economia. Há, também a missão de modernizar os processos de interação entre a Administração Pública e as empresas.

Dessa maneira, o e-government caminha em fases para substituição de documentos impressos por eletrônicos, utilizando como base modelos de governos eletrônicos de outros países. O SPED é um instrumento que unifica as atividades de recepção, validação, armazenamento e autenticação de livros e documentos integrantes da escrituração comercial e fiscal das empresas, por meio de fluxo único e automatizado de informações (Geron, Finatelli, Faria, \& Romeiro, 2011).

Na opinião de Diniz et. al., 2009, o SPED propiciará benefícios para os contribuintes, tais como: a simplificação das obrigações acessórias; eliminação de digitação de notas fiscais na recepção de mercadorias; redução de erros de escrituração que podem levar ao pagamento de multas; a redução de custos com impressão, aquisição de papel e formulários, e armazenamento de documentos, gerando, também impacto ambiental favorável.

O SPED é dividido em três subprojetos: a) nota fiscal eletrônica (NF-e); b) sistema de escrituração digital fiscal (SPED-Fiscal), e c) sistema de escrituração digital contábil (SPED-Contábil). Geron et. al. (2011) destacam que a expectativa de melhoria com o uso do SPED beneficia vários atores, pois empresas poderão ter redução de erros operacionais, considerando que a Nota Fiscal Eletrônica NFe é emitida mediante a validação do sistema on-line do Governo. O fisco terá mais agilidade no acesso às informações dos contribuintes.

De fato, esses benefícios são potencializados, uma vez que o SPED tem como objetivo trabalhar com os arquivos digitais, em substituição aos livros fiscais e contábeis de papel pelos eletrônicos. Há, portanto, um impacto positivo na redução da quantidade de impressos; beneficiando, também o meio ambiente 
e propicia, inclusive, o cultivo da consciência sustentável entre sociedade e Governo. Diante desse contexto de modernização na gestão pública, surge no Estado de São Paulo um Programa de Estímulo à Cidadania Fiscal - a Nota Fiscal Paulista - NFP.

\subsection{Programa de Estímulo à Cidadania Fiscal - Nota Fiscal Paulista - NFP}

De acordo com a Secretaria da Fazenda do Estado de São Paulo - SEFAZ (2015), o principal imposto estadual incidente sobre as empresas é o Imposto sobre operações relativas à Circulação de Mercadorias e Prestação de Serviços de Transporte Interestadual e Intermunicipal e de Comunicação (ICMS). Este imposto é a maior fonte de recursos financeiros para o Estado, situando-se entre os tributos administrados pelas fazendas estaduais e do Distrito Federal.

Carazza (2005, p.35) afirma que o interesse na melhoria da forma de arrecadação pelo ICMS tem sido renovado, uma vez que esse imposto é a principal base de arrecadação dos Estados. Dessa maneira, o fisco busca desenvolver tecnologias que facilitem a fiscalização do cumprimento das obrigações tributárias e aumento da arrecadação.

Pinho (2008, p. 471), por sua vez, destaca ser inegável o crescimento acelerado das Tecnologias de Informação e Comunicação (TIC) nos últimos anos. Esse avanço se dá com a crescente obsolescência existente; configurando, inclusive um possível novo estágio do desenvolvimento das sociedades que coloca, não só enormes possibilidades de mudanças sociais, mas uma série de questões marcadas pelo tempo.

O Governo do Estado de São Paulo sancionou, em 28/08/2007, o Projeto de Lei que dispõe sobre a criação do Programa de Estímulo à Cidadania Fiscal, aprovado pela Assembléia Legislativa do Estado de São Paulo. Toporcov (2009, p. 31) destaca que o Programa da Nota Fiscal Paulista - NFP consiste na devolução de $30 \%$ do ICMS efetivamente recolhido pelo estabelecimento comercial a seus consumidores.

Os consumidores que informarem o seu Cadastro de Pessoa Física (CPF) ou Cadastro Nacional de Pessoa Jurídica (CNPJ), no momento da compra, escolhem como receber os créditos, e ainda concorrem a prêmios em dinheiro, incentivando à adesão ao programa (Toporcov, 2009, p. 31).

O objetivo do programa é estimular os cidadãos que adquirem mercadorias, o hábito de exigir do fornecedor a Nota ou o Cupom Fiscal, visando a: combater a sonegação fiscal; incentivar os adquirentes de mercadorias, bens e serviços de transporte interestadual e intermunicipal a exigir do comerciante a entrega de documento fiscal e reduzir o comércio informal e de produtos ilegais (Siqueira, Oliveira, \& Anjos, 2014). 
Entre os benefícios do programa para o fisco destacam-se: ampliação da base de contribuintes pela demanda por emissão de Notas e Cupons Fiscais; cruzamento eletrônico de informações e aprimoramento dos controles fiscais e a redução da sonegação fiscal possibilitando uma maior arrecadação (SEFAZ-SP, 2015).

No que diz respeito aos benefícios do programa para o consumidor destacam-se: alternativas para utilização dos créditos; distribuição de até $30 \%$ do valor recolhido pelo estabelecimento comercial, proporcional ao valor da nota fiscal; fortalecimento do exercício da cidadania, contribuindo para a redução da sonegação fiscal; participação em sorteios; e programa reduz a carga tributária para o consumidor, sendo que até $30 \%$ do ICMS efetivamente recolhido a cada mês pelo estabelecimento fornecedor é distribuído a todos os compradores que forneceram o numero de cadastro pessoa física (CPF) ou cadastro nacional pessoa jurídica (CNPJ), proporcionalmente ao valor de sua compra (SEFAZ-SP, 2015).

Para o estabelecimento comercial, destacam-se os seguintes benefícios do programa: dispensa de Autorização para Impressão de Documentos Fiscais (AIDF), no caso de emissão exclusiva da Nota Fiscal On-line; fortalecimento do combate à pirataria de produtos; maior isonomia e justiça fiscal, com diminuição da concorrência desleal; redução de custos de aquisição de papel, redução de custos de impressão e armazenagem de documentos fiscais; redução no tempo de guarda (armazenagem) dos documentos fiscais, simplificação das obrigações acessórias e incentiva ao uso de relacionamentos eletrônicos com os contribuintes (SEFAZ-SP, 2015).

O programa caminha no sentido da informatização de documentos em papel, transformando-os em eletrônicos; pois exige que todas as notas emitidas sejam registradas pelos estabelecimentos no banco de dados da Secretaria da Fazenda (SEFAZ-SP, 2015). Estando com o cadastro atualizado, a Secretaria Estadual de Assistência e Desenvolvimento Social (SEADS) poderá ser beneficiada das seguintes formas:

a) Participar dos sorteios mensais da Nota Fiscal Paulista (NFP),

b) Participar dos sorteios mensais da NFP, nos quais a cada $\mathrm{R} \$ 100,00$ (cem reais) em notas fiscais registradas na Secretaria da Fazenda, será atribuído um bilhete eletrônico numerado para concorrer a prêmios em dinheiro.

c) Receber doações de créditos referentes à NFP, e

d) Receber a doação de documentos fiscais sem o CPF ou CNPJ (SEFAZ-SP, 2015).

Os critérios para utilização dos créditos seguem os critérios estabelecidos no programa, conforme divulgados no site da NFP (SEFAZ-SP, 2015). O credito é 
liberado para utilização em dois períodos, sendo: Abril - créditos referentes aos documentos fiscais do 20 semestre do ano anterior e Outubro - créditos referentes aos documentos fiscais do 1 o semestre do ano corrente. Atualmente, o sistema disponibiliza as seguintes formas de utilização do crédito: outubro;

a) pagamento do IPVA do exercício seguinte disponível apenas em

b) transferência dos créditos para outra pessoa física;

c) solicitação do depósito dos créditos para uma conta corrente ou poupança de titularidade do usuário, e

d) doações às entidades paulistas de assistência social e da área da saúde, sem fins lucrativos.

O prazo para resgate dos créditos é de cinco anos, contado da data em que tiver sido disponibilizado pela Secretaria da Fazenda do Estado de São Paulo. Não poderão utilizar os créditos gerados os inadimplentes em obrigações pecuniárias, de natureza tributária ou não tributária, do Estado de São Paulo.

O cálculo dos créditos é realizado após o vencimento dos prazos de registro e de retificação dos documentos fiscais, sendo informado ao consumidor no terceiro ou quarto mês após a data da emissão da nota/cupom fiscal. O prazo é de até 10 (dez) dias úteis, exceto nos casos em que tenham sido informados dados incorretos no momento da solicitação, tais como: números de agência e conta. Neste caso, será realizado o estorno, retornando o valor à conta corrente da Nota Fiscal Paulista (SEFAZ-SP, 2015).

O documento fiscal poderá ter qualquer valor; entretanto, o consumidor terá direito aos créditos proporcionais ao valor de suas compras. O consumidor deverá exigir nos estabelecimentos comerciais emissores de Nota Fiscal Paulista, o documento fiscal no ato da compra, informando seu CPF ou CNPJ.

Após os cálculos dos créditos, o consumidor deverá aguardar a liberação para utilização e selecionar uma das opções disponíveis no sistema. Mercadoria sujeita ao regime de substituição tributária, ou seja, não é o estabelecimento comercial que efetuou a venda que recolhe o imposto, mas sim o fabricante, a operação comercial poderá gerar crédito zero ou créditos, caso o estabelecimento comercial recolha o ICMS referente à venda de outros produtos.

O Governo do Estado de São Paulo implantou em dezembro de 2008 o sorteio de prêmios aos cidadãos que participam do Programa, para incentivar essa participação. Por meio do site da Secretaria da Fazenda do Estado de São Paulo, o Governo disponibiliza informações sobre a execução orçamentária e financeira para conhecimento e acompanhamento da sociedade (SEFAZ-SP, 2015). 
Na sequência, informa os créditos e prêmios distribuídos, números de usuários, notas e cupons fiscais, estabelecimentos cadastrados e números de adesões aos prêmios distribuídos por sorteios. O Programa disponibiliza no site da NFP para seus usuários manuais e aplicativos com o objetivo de facilitar a utilização do sistema.

Cabe destacar que, no Estado de São Paulo, a capital apresenta, também um Programa chamado Nota Fiscal Eletrônica de Serviços - NF-e, em que o cidadão (tomador de serviços) que pedir a emissão da NF-e, poderá utilizar parte do Imposto sobre Serviços - ISS, recolhido para abater até 50\% do Imposto Predial e Territorial Urbano - IPTU (PCSP, 2015). Na sequência, serão descritos os aspectos metodológicos desta pesquisa.

\section{Aspectos Metodológicos}

Esta é uma pesquisa de caráter exploratório (Malhotra, 2011). Para responder à questão central da pesquisa e atender aos objetivos do estudo, foi escolhida a pesquisa do tipo survey (Babbie, 1999). Em relação à coleta de dados, utilizou-se amostra não-probabilística e, sim intencional e por conveniência. A partir do referencial teórico-conceitual foi proposta a conjectura de que existam padrões de utilização de incentivos e uso do programa Nota Fiscal Paulista pelos contribuintes da Geração Y.

Operacionalmente, os dados obtidos foram tabulados e transformados em gráficos, a partir da suposição de que os comportamentos seriam iguais. Para avaliação do comportamento na utilização do Programa de Estímulo à Cidadania Fiscal, utilizou-se a metodologia apresentada por Richardson (2008) na elaboração da pesquisa.

Participaram desta pesquisa, realizada em Agosto de 2011, 117 indivíduos; sendo 83 estudantes da faixa considerada Geração Y, ou seja, nascidos entre 1980 e 1999 e 34 estudantes de gerações anteriores, de acordo com a faixa etária identificada na pesquisa. Os participantes são moradores da Grande São Paulo.

Para o levantamento dos dados necessários à realização deste estudo, foi utilizado um instrumento de coleta contendo dez questões fechadas e uma questão aberta, contemplando questões sobre o grau de conhecimento do cidadão sobre o Programa da NFP, sobre o cadastro e utilização do sistema; sobre a solicitação da NFP a cada compra e sobre a utilização dos créditos; bem como sobre a frequência com que monitora seus créditos e sua consideração em relação aos benefícios que este programa proporciona para os diversos atores na cadeia tributária: Fisco; Contribuinte; Cidadão/Consumidor; Entidades Assistenciais e Sociedade em Geral. 
Os sujeitos desta pesquisa receberam pessoalmente os questionários, que foram recolhidos depois de respondidos pelos participantes. Posteriormente, os dados foram compilados e foram tratados. Por seu caráter exploratório, a análise dos resultados pesquisa limitou-se a procedimentos estatísticos descritivos (Diehl, Souza, \& Domingos, 2007).

Freund e Simon (2000) consideram que a Estatística Descritiva possui limitações ligadas, pelo fato de os dados serem, costumeiramente, obtidos em amostras por conveniência e intencionais, tal como no caso deste artigo; o que incita generalizações por parte dos pesquisadores que analisarão os resultados. Foram utilizados gráficos de barra, pizza, de caixa e folhas; essa utilização foi oportuna, por facilitar a evidenciação de possíveis tendências do fenômeno de comportamento da Geração Y em relação à NFP.

\section{Descrição e Análise dos Resultados}

Com auxílio da análise exploratória de dados por gráficos, os resultados serão comentados. As respostas às questões de pesquisa foram analisadas, e uma vez confrontadas com o referencial teórico, fundamentarão as conclusões finais. Dessa forma, buscou-se responder às questões sobre a preferência de utilização dos créditos da NFP pela Geração Y e as evidências de benefícios da adoção da referida nota sob a ótica do cidadão.

Os sujeitos do grupo da Geração Y (83 identificados) pesquisada possuem idade mínima de 16 e máxima de 30 anos. Dos respondentes da pesquisa, 30\% são do sexo masculino e $70 \%$ são do sexo feminino; sendo que destes, $43,59 \%$ possuem pós - graduação lato sensu; 5,13 \% graduação; 28,21\% ensino médio e $23,08 \%$ ensino médio com curso técnico.

Gráfico 1: Cadastramento no Portal da NFP 


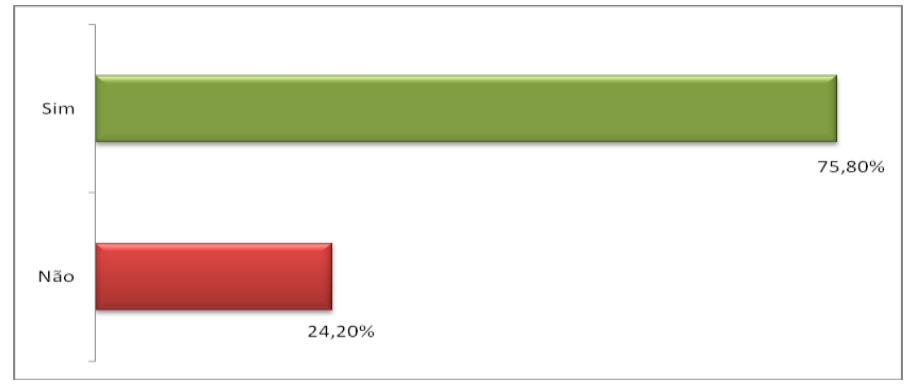

Fonte: Dados da pesquisa (2011).

Conforme Gráfico 1, pode-se verificar que $75,8 \%$ dos respondentes que pertencem à Geração Y cadastraram-se no Portal da Secretaria da Fazenda do Estado de São Paulo para o Programa de Incentivo à Cidadania Fiscal. Aparentemente, o resultado pode expressar maior propensão desse grupo em participar do programa.

Em termos conceituais, essa informação corrobora a expectativa desse grupo quanto à maior facilidade com uso de sistemas de informação e seu maior engajamento com a política e-government. Em relação ao uso do crédito, existem algumas possibilidades, a serem vistas no Gráfico 2:

\section{Gráfico 2: Preferência de uso do crédito da NFP}

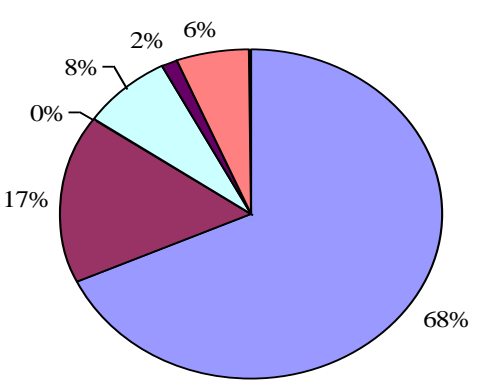

口 CRÉDITO EM CONTA CORRENTE

$\square$ DESCONTO NO IPVA

$\square$ DOAR PARA ENTIDADES

ASSISTENCIAIS

口OUTROS

- REPASSAR O CREDITO PARA

OUTRA PESSOA

$\square$ NÃO RESPONDEU

Fonte: Dados da pesquisa (2011).

Pode-se verificar no Gráfico 2, os possíveis usos dos créditos da NFP: crédito em conta corrente, desconto no Imposto sobre a Propriedade de Veículos Automotores - IPVA, doação para entidades sociais, repasse do crédito para outra pessoa, não respondentes e outros.

Identificou-se que a preferência de utilização dos benefícios da nota fiscal paulista por parte do grupo analisado é crédito em conta corrente, com $68 \%$ da preferência; seguidos de $17 \%$ que opta pelo desconto no IPVA. Em relação à 
consulta dos créditos, os cidadãos têm diversos hábitos, a serem vistos no Gráfico 3.

\section{Gráfico 3: Frequência de consulta dos créditos}

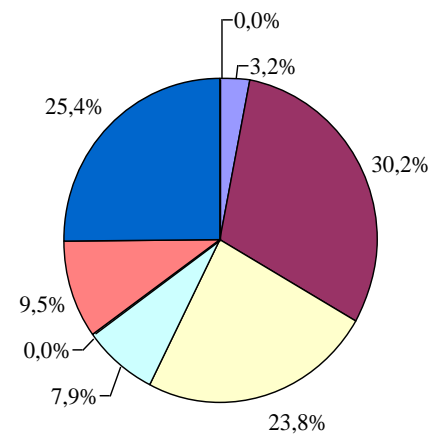

Fonte: Dados da pesquisa (2011).

\author{
DIARIAMENTE \\ - MENSALMENTE \\ $\square$ NÃO CONSULTO/MONITORO \\ 口OUTROS \\ - SEMANALMENTE \\ 口 SEMESTRALMENTE \\ $\square$ TRIMESTRALMENTE \\ $\square$ (vazio)
}

Pode-se verificar, no Gráfico 3, que o grupo selecionado consulta, em sua maioria $(30,2 \%)$, mensalmente os créditos. Há, contudo, uma participação relevante daqueles que consultam trimestralmente de $25,4 \%$ em relação às alternativas indicadas: diariamente, mensalmente, semestralmente, não consulta/monitora, semanalmente, semestralmente, trimestralmente e outros. Assim, o grupo mostrou evidencias que corroboram o aspecto de busca pelos seus direitos para os participantes da Geração Y. A facilidade de cadastramento em relação às faixas etárias pode ser evidenciada no Gráfico 4.

Gráfico 4: Facilidade para cadastramento 


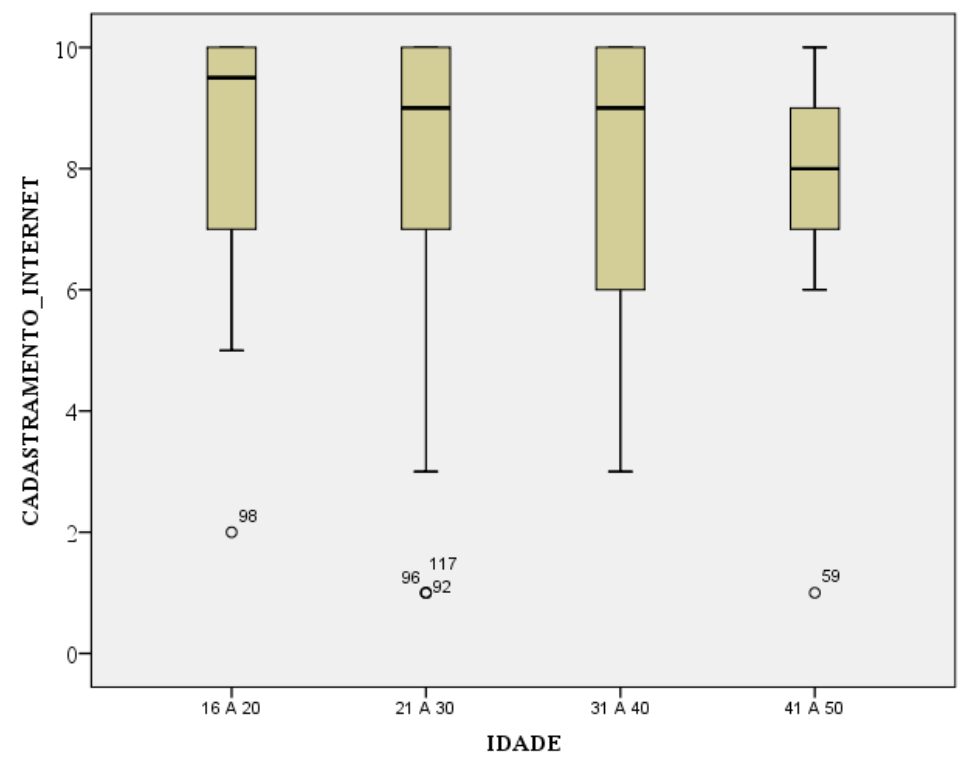

Fonte: Dados da pesquisa (2011)

Conforme apresentado no Gráfico 4, a faixa etária entre 16 a 20 anos possui maior facilidade para cadastramento. Cabe destacar que as faixas entre 21 a 30 e entre 31 a 40 anos mantêm no mesmo nível de acesso ao cadastro. Já para a faixa mais distante da Geração $Y$, ou seja, acima dos 41 anos, não demonstrou a mesma facilidade para o cadastramento no programa. Identificase, assim, que a Geração Y tem maior facilidade na utilização de ferramentas ligadas às tecnologias de informação.

O comportamento próximo das três primeiras faixas pode ser explicado pela dificuldade de demarcação em termos temporais da Geração Y. É possível que exista um caráter de transição ou maior influência entre as faixas etárias mais próximas. Esse fenômeno repete-se, no que diz respeito à facilidade para consulta e monitoramento dos créditos, mas se contraria em relação às rotinas de controles:

Gráfico 5: Facilidade para consulta e monitoramento de créditos 


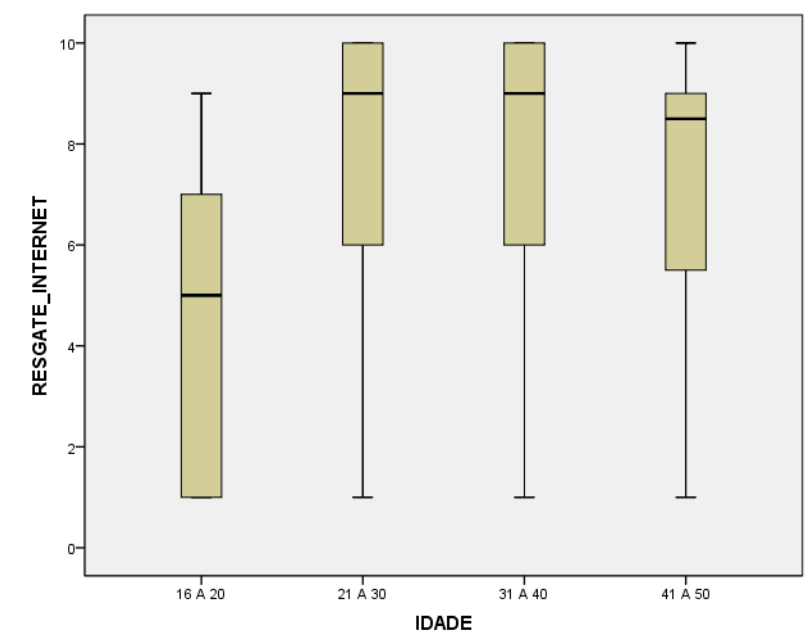

Fonte: Dados da pesquisa (2011)

Conforme Gráfico 5, a faixa etária entre 16 a 20 anos, a mais jovem da chamada Geração Y, por sua vez, não consulta ou monitora seus créditos. Apesar de destacarem-se no uso de tecnologias, identificou-se que estes jovens não estão habituados à rotina de acompanhamento dos benefícios gerados por apuração no período, o que para as demais faixas etárias manteve-se equilibrado. Em relação à teoria, o comportamento de baixo monitoramento pode estar associado ao atributo de impaciência, característica desvantajosa dos integrantes da Geração Y.

\section{Gráfico 6: Facilidade para resgate dos créditos}

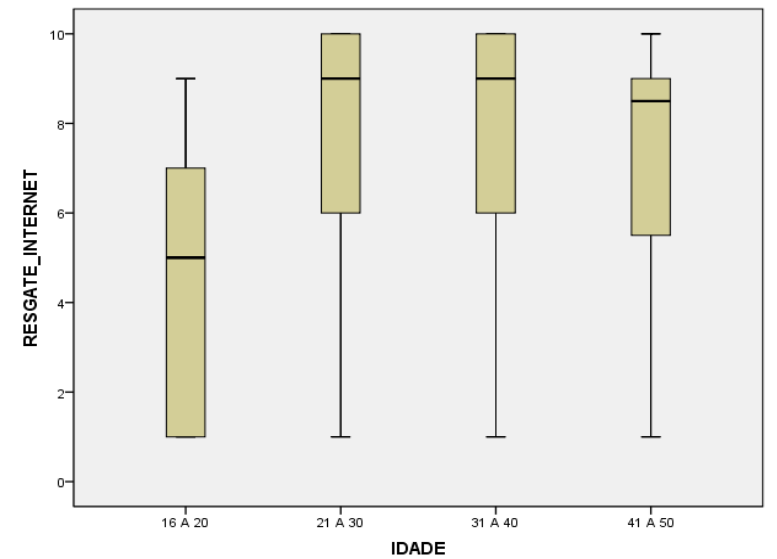

Fonte: Dados da pesquisa (2011)

Pode-se verificar no Gráfico 6 , que não há maior facilidade no uso da Geração $Y$, faixa etária abaixo dos trinta anos de idade em relação às demais faixas apresentadas. Porém, pode-se defender que exista maior facilidade no cadastramento, consulta/ monitoramento e resgate, conforme apresentado nos 
Gráficos 4 e 5; bem como uma relação quando comparada às demais faixas identificadas na pesquisa, fora do grupo considerado Geração Y - dos nascidos entre 1980 e 1999. Essa informação corrobora com a expectativa de que os indivíduos da Geração Y possuem maior facilidade no uso de novas tecnologias e programas informatizados.

\section{Considerações Finais}

O presente estudo permitiu a discussão do Programa de Estímulo à Cidadania Fiscal Nota Fiscal Paulista - no contexto da Geração Y. Pode-se documentar que o objeto do estudo está no contexto de legislação e administração tributárias que exigem do cidadão uma rápida adaptação para que as novas regras sejam seguidas.

Nesse sentido, demonstrou-se o empenho do fisco em fortalecer e desenvolver instrumentos que garantam uma arrecadação mais eficiente e de meios que facilitem o acesso e controle pelo contribuinte e a Administração Pública. Colocou-se em evidência a tendência de modernização quanto ao cumprimento das obrigações tributárias e a intenção do Governo de, cada vez mais, lançar mão das tecnologias, tal como Governo Eletrônico (e-government) para facilitar o acesso do contribuinte e aumentar a eficiência/valor dos processos de gestão fazendária.

Pode-se perceber que o efeito do programa da Nota Fiscal Paulista é positivo no Estado de São Paulo no âmbito do fisco, dos contribuintes e dos cidadãos. A aplicação do instrumento de pesquisa capturou um senso de comprometimento e percepção de benefícios quanto a maioria dos sujeitos que já haviam se cadastrado no programa. O cidadão representa uma figura participativa e ativa no processo tributário baseado na Nota Fiscal Paulista.

Os achados da pesquisa possibilitam responder às questões de pesquisa que constam na Introdução deste trabalho, e defender que há forte adesão da amostra pesquisada pertencente à Geração $Y(75,8 \%)$, cadastrando-se no sistema da NFP. Em termos de forma de uso dos benefícios do programa, parcela significativa dos respondentes $(68 \%)$ dessa faixa prefere o crédito em conta corrente; seguidos de $17 \%$ que opta pelo desconto no IPVA.

Em torno de 30,2\% dos 83 respondentes da pesquisa monitoram, pelo menos uma vez ao mês, seus créditos da NFP. A faixa etária entre 16 a 20 anos possui maior facilidade para cadastramento, e as faixas entre 21 a 30 e entre 31 a 40 anos mantêm-se no mesmo nível de acesso ao cadastro.

A faixa acima dos 41 anos (34 respondentes) não demonstrou a mesma facilidade para o cadastramento no programa, o que se repete para a consulta e monitoramento e para o resgate dos créditos. As estatísticas descritivas 
corroboram com o quadro teórico-conceitual de que os representantes da Geração $Y$ são hábeis na utilização de ferramentas ligadas a Tl; tal como o sistema da NFP e são atentos aos seus direitos e inclinados a buscarem retornos imediatos.

O objetivo do estudo foi atendido, pois foi explorado o comportamento de uma amostra de 83 cidadãos paulistanos da Geração Y em relação ao sistema da NFP. Assim, pode-se obter informações sobre mudanças inerentes desse fenômeno e avaliar até que ponto foram obtidos benefícios, tanto para o cidadão quanto para o órgão fiscalizador.

Não são frequentes estudos que tenham como objeto de estudo a percepção do cidadão sobre sistemas utilizados pelo Governo, fato que antecipa uma contribuição acadêmica com novos achados sociais, justificando a presente pesquisa que utiliza uma abordagem interdisciplinar ao combinar conhecimentos de Administração e Tecnologia da Informação (TI).

A presente pesquisa explorou um tema com característica inovadora, permitindo vislumbrar futuras pesquisas sobre o comportamento do contribuinte em relação a outros aspectos a exemplos de resgate e monitoramento do programa de estimulo à cidadania fiscal.

Dessa maneira, considera-se que este trabalho contribua para a Administração Pública, bem como para a Gestão Social, já que envolve as práticas dos cidadãos de uma geração diante de uma nova ferramenta, que visa ao incentivo do recolhimento dos tributos para o bem-estar social.

Futuras pesquisas podem utilizar testes estatísticos inferenciais para suportar novos achados, bem como o desenvolvimento de estudos futuros que comparem os programas estaduais de Notas Fiscais Eletrônicas que, também são potenciais geradores de novas evidências no campo interdisciplinar da Administração Pública, Contabilidade e Tecnologia da Informação.

\section{Referências Bibliográficas}

Almeida, Jarbas Thaunahy Santos. (2011). E-governo nos municípios do ABC Paulista. Acessado em 19 de Maio de 2015, de http://www.compolitica.org/home/wp-content/uploads/2011/01/sc_ipjarbas.pdf.

Andrade, Carla Coelho. (2010). Juventude e políticas públicas no Brasil. Desafios do Desenvolvimento. Brasília. Ano 7. (60), 45.

Babbie, Earl. (1999). Métodos de pesquisas de Survey. Tradução de Guilherme Cezarino. Belo Horizonte: Editora da Universidade Federal de Minas Gerais. 
Brasil. (2015). O Gov.br - Governo Eletrônico. Acessado em 19 de Maio de 2015, de http://www.governoeletronico.gov.br/o-gov.br.

Chain, Ali., Cunha, Maria Alexandra, Knight, Peter T., \& Pinto, Sandra. L. (2004). E-gov.br: a próxima revolução brasileira. São Paulo: Prentice Hall.

Coelho, Espartaco Madureira. (2001). Governo eletrônico e seus impactos na estrutura e na força de trabalho das organizações públicas. Revista do Serviço Público, 52 (2), 110-130.

Diehl, Carlos Alberto, Souza, Marcos Antonio., \& Domingos, Laura Elaine Cabral (2007). O uso da estatística descritiva na Pesquisa em Custos: Análise do XIV Congresso Brasileiro de Custos. ConTexto, 7 (12), 1-24.

Diniz, Eduardo Henrique, Barbosa, Alexandre Fernandes, Junqueira, Álvaro Ribeiro Botelho., \& Prado, Otavio (2009). O Governo Eletrônico no Brasil: Perspectiva histórica a partir de um modelo estruturado de análise. Revista de Administração Pública, 43 (1), 23-48.

Fernandes, Andréa Campos Gomes (2004). Algumas questões para o futuro. São Paulo: Prentice Hall.

Fregonesi Junior, Maucir. (2010). Sistema tributário nacional: doutrina prática e reforma. São Paulo: Quartier Latin.

Freund, John. E., \& Simon, Gary. A. (2000). Estatística aplicada. 9a. Ed. Porto Alegre: Bookman.

Fugini, Mariagrazia. G., Maggiolini, Piercarlo., \& Pagamici, Bruno. (2005). Por que é difícil fazer o verdadeiro "Governo Eletrônico"? Revista Produção, 15 (3), 300-309.

Geron, Cecília. M. S., Finatelli, João. R., Faria, Ana. Cristina., \& Romeiro, Maria do Carmo (2011). SPED - Sistema Público de Escrituração Digital: Percepção dos Contribuintes em relação aos impactos da adoção do SPED. Revista de Educação e Pesquisa em Contabilidade, 5 (2), 44-67.

Haldenwang, Christian von. (2004). Electronic Government (E-Government) and Development Does the Digital Divide Contribute to the Governance Divide? Proceedings. IN: EADI-conference in Ljubljana.

Kotler, Philip., \& Keller, Kevin L. (2006). Administração de marketing. 12a. Ed. São Paulo: Pearson.

Lemos, André., \& Levy, Pierre. (2010). O futuro da internet: em direção a uma ciberdemocracia planetária. São Paulo: Paulus. 
Lipkin, Nicole., \& Perrymore, April. (2010). A geração Y no trabalho. Trad. Bruno Alexander. Rio de Janeiro: Campus.

Malhotra, Naresh K. (2011). Pesquisa de marketing: uma orientação aplicada. Tradução de N. M. Jr. e A. A. de F. 5ạ. Ed. Porto Alegre: Bookman.

Mattos, Enlinson, Rocha, Fabiana., \& Toporcov, Patrícia F. (2013). Programas de incentivos fiscais são eficazes? Evidência a partir da avaliação do impacto do programa nota fiscal paulista sobre a arrecadação de ICMS. Revista Brasileira de Economia, 67 (1), 97-120.

Mora, Mônica. (2005). Governo eletrônico e aspectos fiscais: a experiência brasileira. Rio de Janeiro: IPEA. Acessado em 19 de Maio de 2015, de http://portal2.tcu.gov.br/portal/pls/portal/docs/2063226.PDF.

Oliveira, Sidnei. (2010). Geração Y: o nascimento de uma nova gestão de líderes. 2ª. Ed. São Paulo: Integrare.

Paula, Ana Paula Paes. (2005). Por uma nova gestão pública. Rio de Janeiro: FGV.

PCSP - Prefeitura da Cidade de São Paulo. (2010). Nota Fiscal Eletrônica de Serviços - NF-e. Acessado em 19 de Maio de 2015, de http://nfpaulistana.prefeitura.sp.gov.br/arquivos/manual/Manual_NFe_PJ.pdf.

Pereira, Sidinei. A., Locks, Rosilene, Matos, Duilo. S., \& Costa, Gleimiria B. (2008) Governança eletrônica na administração pública: estudo de caso sobre a nota fiscal eletrônica - NF-e. Anais... IN: XVIII Congresso Brasileiro de Contabilidade, Gramado.

Pinho, José Antonio Gomes. (2008). Investigando portais de governo eletrônico de estados no Brasil: muita tecnologia, pouca democracia. Revista de Administração Pública (RAP), 42 (3), 471-493.

Richardson, Roberto Jarry. (2008). Pesquisa social. 3ạ. Ed. São Paulo: Atlas.

Rocha, Ângela da., \& Christensen, Carl. (2008). Marketing: teoria e prática no Brasil. 2a. Ed. São Paulo: Atlas.

Schedler, Kuno., \& Scharf, Maria C. (2001). Exploring The Interrelations Between Electronic Government And The New Public Management. A Managerial Framework For Electronic government. Proceedings... IN: I3E Conference Zurich.

SEFAZ - Secretaria da Fazenda do Estado de São Paulo. (2011). Produtos e serviços: ICMS. São Paulo. Acessado em 19 de Maio de 2015, de http://www.fazenda.sp.gov.br/oquee/oq_icms.shtm. 
Siqueira, Andreia Diniz A. A., Oliveira, Celene S., \& Anjos, Raquel P. (2014). Nota fiscal paulista: uma estratégia para reduzir a sonegação fiscal. Revista InterAtividade, 1 (1), 1-9.

Toporcov, Patrícia F. (2009). Evidências empíricas do efeito da nota fiscal paulista e alagoana sobre a arrecadação estadual. Dissertação (Mestrado em Economia) - Escola de Economia de São Paulo da Fundação Getúlio Vargas, São Paulo.

Recebido em 28/08/2014

Aceito 28/11/2014 